\title{
METODOLOGIESE VRAAGSTUKKE VAN DIE GEESTESWETENSKAPPE
}

\author{
Johann Mouton \\ Afdeling Navorsingsmetodologie INO, RGN.
}

Dic oogmerke met hierdie artikel is dricërlei: (1) Om dic betckenis van metodologie nader te ekspliseer; (2) aan te dui wat die verband tussen metodologiese en wetenskapsfilosofiese vraagstukke is en (3) 'n aantal navorsingsvoorkeure op dic gebied van die metodologie van die gecsteswetenskappe te lys.

\section{WAT IS 'N METODOLOGIESE VRAAGSTUK?}

Wanneer 'n opgaal van metodologiese vraagstukke gemaak moet word, is 'n klaarblyklike probleem die verskeidenheid van betekenisse wat aan die woord metodologie geheg word en die daaruit voortvlociende stereotıpes wat in dic navorsingsliteratuur gevestig raak. As in gedagte gehou word dat dit tradisioneel slegs twee groepc is - die wetenskapsfilosowe en, meer onlangs, sosiale statistick - wat hulle met besinning oor die aard van wetenskaplike navorsing (in 'n voorskriftclike sin) besig hou, is dit daarom ook begryplik waarom veral twee stercotipes oor dic aard en terrcin van die navorsingsmetodologie posgevat het.

(1) Transendentalistiese stereotipe:

Vanuit wetenskapsfilosofiese kringe word tipies gevra na die voorwaardes en vooronderstellings waaronder wetenskap plaasvind. Vanuit hierdie dissipline word die taak van die metodologie - wat dikwels as 'n deelsdissipline van die logika of epistemologic gedefinieer word - daarom as grondslaekritiek gesien. In 'n resente werk bevraagteken Barry Hindess die fundamentele aard van so 'n onderneming.' Volgens hom berus die transendentalistiese raamwerk op die aanname dat filosofie die reg het, op grond van 'n besondere kennisbegrip, om riglyne aan vakwetenskaplikes oor die kriteria van gocie navorsing te formuleer. Hy stel die besondere taak van sy boek daarom ook soos volg: "In this book I intend to expose and to destroy the myths of methodology and, in particular, philosophy's claims to an esoteric 'knowledge' from which these myths derive".?

Dic basiesc probleem met hicrdie beskouing oor metodolgie is, volgens

Koers, 48(3) 1983 
Hindess, in ' $n$ intrinsieke sirkelredenasie geleë:

"The inescapable circularity of epistemology is evident for, however, it may conceive the distinction between knowledge and the world, its theory of knowledge logically presupposes a knowledge of the conditions in which knowledge takes place, that is, of the terms of the opposition, 'subject' and 'object', and of the nature of the relation between them. Thus the epistemological specification of the criteria of the validity of all knowledge must presuppose the validity of the prior 'knowledge' from which that specification is derived". ${ }^{3}$

Alhoewel ek meen dat Hindess se argument nie water hou nie, stem ek saam met sy diagnose van die probleem, nl. dat die transendentalistiese model van metodologie gebaseer is op die aanname dat die wetenskapsfilosofie/epistemologie eksklusiewe toegang tot die voorwaardes van navorsing het.

\section{(2) Tegnisistiese stereotipe}

'n Resenter interpretasie van die terrein van die metodologie, soos ook duidelik in die meerderheid handboeke in die geesteswetenskappe na vore kom, het sy oorspronge in die statistiek. In 'n onlangse evaluering van die terrein van die metodologie wys Irwin Sperber op hierdie interpretasie: "Because of the tendency to emphasize proficiency in quantitative and survey research in sociology, a misleading stereotype of the methodologist as a narrowly trained statistician or technician is sometimes uncritically accepted". "Vanuit hierdic model word die taak van die metodologie gereduseer tot die beskrywende studie van die toepaslikheid van spesifieke statistiese en wiskundige tegnieke in die navorsingsproses.

Waar die transendentalistiese stereotipe aan die tipiese preskriptivistiese sindroom van baie wetenskapsfilosowe ly, vertoon die tegnisistiese stereotipe die teenoorgestelde tendens: 'n onkritiese aanvaarding van die beskikbare tegnieke waar die enigste kriteria doeltreffendheid en toepaslikheid is. My eerste argument kom dus daarop neer dat beide hierdie benaderings ontoereikend is en dat die werklike terrein van die navorsingsmetodologie êrens tussen hierdie twee stereotipes geleë is.

Die geesteswettenskaplike navorsing het tipies behoefte aan riglyne en modelle op vrae soos die volgende:

- Hoe bepaal my keuse vir ' $n$ bepaalde navorsingstrategie die keuse van metodes en tegnieke en uiteindelik ook die geldigheid en betroubaarheid van my bevindinge? 


\section{Mouton}

- Watter faktore specl 'n rol (behoort 'n rol te specl) in my ontwerp van 'n navorsingsprojek?

- Wat is die relatiewe voor- en nadele verbonde aan verskillende navorsingsontwerpe, bv. eksperimentele versus kwasi-eksperimente versus kwalitatiewe ontwerpe, en watter implikasies het my keuse vir 'n bepaalde ontwerp?

- Watter begrensingc EN vereistes stel dic navorsingsubjek en die geformulecrde navorsingstaak aan my keuse van tegnieke van konseptualisering, data-insameling en dataontleding?

- Hoc beïnloed my keuse vir 'n sekere metodologiese en teoretiese paradigma dic besluite wat ek tydens navorsing neem?

Hicrdie vrae verskil enersyds van die meer filosofies-teoreticse vrac van die wetenskapsfilosofie daarin dat dit klem lê op die reele besluite en die verantwoording van daardie besluite wat dic individucle navorser tydens die navorsingsonderneming neem. Dit verskil ook andersyds van die spesifick tcgnicse aspckte van navorsing waarmce statistici, wiskundiges en rekenaarwetenskaplikes hulle besig hou. Wat laasgenoemde betref, is dit vanselfsprekend dat 'n navorser op 'n gegewe oomblik 'n besluit moet neem ten gunste van een tegniek eerder as 'n ander. Die fout van die tegnisistiese benadering is om te aanvaar dat sodanige beslissing slegs op grond van tegniese oorwegings geneem word. Wanneer metodologie as die afweeg van tcgnieke gedefinieer word, moet cerder van die domein van die navorsingstegnologic ${ }^{5}$ gepraat word. Word daarmee egter die hele konteks van navorsingsbesluitneming bedocl, wat die epistemologiese, ontologiese en wetenskapsfilosofiese faktore insluit, wat in die besluitnemingsproses meespecl, kan van die terrein van dic navorsingsmetodologie gepraat word.

Kenmerkend van die metodologic is die funksionalistiese aard van die vrac waarvoor antwoorde gesock word, d.w.s. dic beklemtoning van die interaktiewe aard van besluite in die navorsingsaktiwiteit. Anders gestel: my besluit om tegnick $A$ te gebruik, word onder meer bepaal deur my vroecre besluite oor navorsingsontwerp en dic doelstelling van die besondere projek. Besluite in die navorsingshandeling, soos in enige menslike bedrywigheid, hang tipies funksioncel saam. Dic funksionalistiese tcrminologic wat $\mathrm{ck}$ in my omskrywing van dic terrcin van die navorsingsmetodologic ge:bruik (vergclyk die volgende afdeling), moet cgter nie verstaan word as sou die navorsingsaktiwitcit analoog aan 'n selfaangedrewe sisteem beskou word nie. Dit gaan deurentyd vir my om die funksionaliteit van besluite, d.w.s. besluite wat redelik en verantwoordbaar moet wces op grond van beredenering, oorweging, nadenke, kritick cnsovoorts in die lig van die cise wat aan goeie 


\section{Metodologiese vraagstukke}

wetenskaplike navorsing gestel word. Die taak van die navorsingsmetodologie is daarom duidelik: om riglyne en beginsels te formuleer ten einde die navorser in staat te stel om meer verantwoorde, rasionele besluite in die navorsingsaktiwiteit te kan neem. Dit impliseer nòg afgeslote resepte of onbetwyfelbare tegniese algoritmes wat die navorser 'n ABC tot geslaagde navorsing bied, nòg esoteriese filosoliese caveats oor die moete en moenies van navorsing. Veel eerder moet die navorser bewus gemaak word van die feit dat sy besluitneming, soos in alle redelike handelinge, ingebed is in sy totale bestaansmodus en onwillekeurig elemente van sy agtergrond, dissiplinêre matriks, opleiding, persoonlikheid ensovoorts sal insluit.

Hierdie laaste gevolgtrekking impliseer dat die navorsingsmetodologie nie in isolasie oor metodologiese vraagstukke mag besin nie maar insette vanuit 'n verskeidenheid van dissiplines sal moet insluit, waaronder die statistiek, rekenaarwetenskap, wetenskapsfilosofie, epistemologie, logika, etiek, wetenskapssosiologie. Ek staan in die volgende afdeling stil by die verband tussen navorsingsnetodologie en wetenskapsfilosofie.

\section{NAVORSINGSMETODOLOGIE EN WETENSKAPSFILOSO- FIE}

In die lig van die bespreking tot dusver verduidelik ek hierdie verband aan die hand van 'n model van die wetenskaplike navorsingsaktiwiteit. Die model wat ek hanteer - en tentatief die sisteemteoretiese model van geesteswetenskaplike navorsing noem - is aangepas uit die werke van Gerard Radnitzky ${ }^{6}$ en Thomas Kuhn. ${ }^{7}$ Van die wysigings aan hulle modelle is genoodsaak omdat beide modelle as modelle vir die natuurwetenskappe ontwerp is.

Die drie subsisteme: komponente en intersistemiese relasies (Figuur 1)

Drie subsisteme van die sisteem WETENSKAPLIKE NAVORSINGSPRAK'TYK word onderskei: INTELLEK'TUELE KLIMAAT' (IK), MAKK VAN INTELLEKTUELE HULPBRONNE (MIH)en die NAVORSINGSPROSES (N). Die konteks is 'n geesteswetenskaplike dissipline (sosiologie, sielkunde, geskiedenis ensovoorts). Die basiese punt wat met hierdie model geillustreer word, is dat die individuele navorser in die navorsingsproses $(N)$ insette vanuit die subsisteme IK en $\mathrm{MIH}$ selektief internaliseer ten einde hom in staat te stel om in vrugbare wisselwerking met sy navorsingsonderwerp/voorwerp in die betrokke navorsingsdomein te tree en wetenskaplik aanvaarde navorsingsprodukte te lewer. 


\section{Mouton}

Die subsisteme IK en MIH dui dus op daardie sisteme in 'n bepaalde dissipline waaruit individucle navorsers sekere insettc (metateoretiese aannames, tcorieë, modelle, konscpte, metodes en tegnieke) kan selckteer ten einde docltreffend navorsing te kan doen. Ek begin met 'n kort bespreking van hierdie twee.

\section{(a) Intellektuele klimaal (IK)}

Die intellektuele klimaat van 'n dissipline dui op daardie versameling mela-tcoretiese aannames wat kollekticf deur die lede van die dissipline gehuldig word. Sodanige aannames strek van meer algemene aannames oor die mens tot die meer domeingerigte aannames oor die aard van die sosiale, kulturele, historiese, ekonomiese ensovoorts. In 'n vak soos sosiologie bestaan die IK dus uit sekere mensbeelde (antropologiese aannames), byvoorbeeld behaviourisme, humanisme, eksistensialisme, simboliese interaksionisme, en aannames oor die aard van die samelewing (meganisties/organisties/sibernetics/simbolies-konseptueel), die aard van tussenmenslike relasies (kousalisties/interaksionisties/sibcrneties) cnsovoorts.

\section{(b) Mark san inlelleklucle hulpbronne (MIH)}

Die mark van intellektuele hulpbronne dui op daardie teorieë (en modelle/Hipoteses) en wetenskapsbeelde wat kollektief deel is van die dissiplinêre tradisie. Wat teorieë in die sosiologie byvoorbeeld betref, sou 'n mens 'n verdere onderskeiding kon tref tussen meer makrososiologiese teorieë (struktuurfunksionalisme, konflikteorie ensovoorts) en meer probleemgerigtc teorieë soos Simon en Gagnon se teorie oor homoseksuele gedrag of Davis en Moore se teorie oor sosiale stratifikasie. Teorieë (en modelle/tipologieë) vorm die belangrikste voedingsbodem vir individuele navorsing deurdat dit nuwe hipoteses, probleme, konsepte ensovoorts genereer.

Wat die wetenskapsbeelde betref, sluit ons hier aan by die bespreking van die terrein van die wetenskapsfilosofie in die ecrste gedeclte. Die wetenskapsfilosofie probeer antwoorde bied op vrae soos: Wat is die aard van waarheid/rasionaliteit/vooruitgang/ensovoorts? Wat is die verband tussen domeinaannames en epistemologiese aannames? Watter model van wetenskaplike groei weerspieël die aard van geslaagde navorsing die beste? Versamelings antwoorde op vrac soos hicrdie vorm saam 'n wetenskapsheeld, bv. positivisme, fenomenologie, hermeneutiek, Neo-Marxisme ensovoorts. 


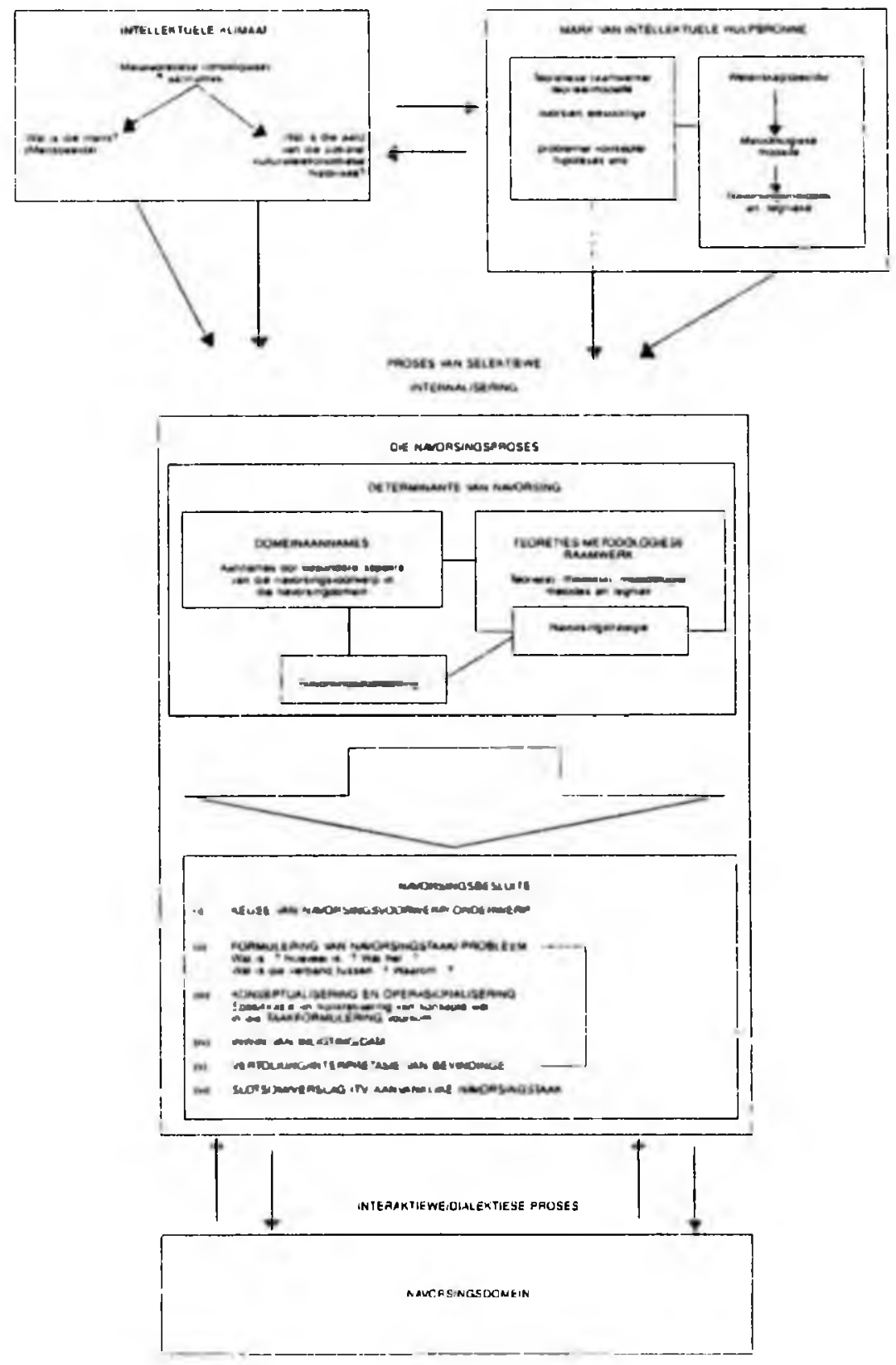




\section{Mouton}

Uit hicrdie bespreking volg dit vanselfsprekend dat die wisselwerking in en tussen dic subsisteme hoog is. Aannames oor wat die aard van sosiale verskynsels is, hou ooglopend verband met watter tcoricë en aan watter wetenskapsbeeld voorkeur gegee gaan word. Die omgekeerde geld ook.

\section{(c) Die navorsingsproses $(\mathcal{N})$}

In die subsisteem NAVORSINGSPROSES onderskei ons tussen die determinante van die navorsingsproses en die (besluitnemings-)stappe tydens navorsing. Dic brandpunt verskuif ook nou in hierdie subsistcem van die breë dissiplinère konteks na die besondere situasie van die individuele navorser.

(i) Determinante van die navorsingsproses. Uitgaande van 'n geformulecrde navorsingstaak hanteer dic navorser (soms cerder implisiet as eksplisiet) sekere aannames oor sy navorsingsdomein en navorsingsonderwerp; 'n sekere teoretiese raamwerk of teorie(ë); 'n betrokkc wetenskapsbeeld en daaruit voortvlociende metodologiese voorkeure, tegnicke, ensovoorts. In my model definicer ek hierdie geselekteerde en geïnternaliscerde faktore wat die navorser uit die subsisteme IK en MIH as insette vir sy betrokke navorsing mobiliscer, as determinante van die navorsingsproses. ${ }^{4}$

Die keuse van watter insette uit die IK en MIH gesclekteer gaan word, geskied onder leiding van die teoretiese en metodologiese eise van die navorsingstaak. Op soortgelyke wyse word die doel van sy navorsing (verkennend/beskrywend/analities/prognosties) en navorsingstrategic (universele/nomotetiese versus kontekstuele/idiografiese strategie) beïnvloed deur beide IK - en MIH-insette en die besondere eise van die navorsingst aak. Die geselekteerde en geïnternal iseerde dissiplinêre insette - die domeinaannames/tcoretiese en metodologiese raamwerk/ensovoorts - bepaal egter in 'n baie sterk sin die besluite van die navorser. Geen navorser, hoe bewus of onbewus hy ook al daarvan mag wees, neem besluit in 'n vakuum nie. Daardic waardes en aannames - oor' $n$ verskeidenheid van navorsingsrelevante sake - wat hy in sy navorsingsloopbaan deur 'selekt iewc internalisering' sy eie gemaak het, bepaal inderdaad die aard van sy besluitneming.

(ii) (Besluilnemings-)slappe in die navorsingsproses. Vanaf dic aanvanklikc formulering van die besondere navorsingstaak of -problecm tot en met die voltooiing van die navorsing moet die navorser deurentyd oor' $n$ verskeidenheid van metodologiese en tegnologiese probleme besin en moet hy gegronde beslissings hicroor necm. In hierdie proses word sy besluite oor konseptualisering, operasionalisering, data-insameling, dataverwerking en 


\section{Metodologiese vraagstukke}

-ontleding, interpretasie en verslagskrywing deurentyd beïnloed deur die navorsingsdoelstelling, navorsingstrategie, domeinaannames, teorieë ensovoorts, dit wil sê die determinante van die navorsingsproses.

Vanuit hierdie model volg dit, myns insiens, duidelik in watter verhouding wetenskapsfilosoliese en navorsingsmetodologiese arbeid tot mekaar staan. Ek begin met die terrein van die navorsingsmetodologie.

Ek het vroeër die terrein van die navorsingsmetodologie in terme van die funksionaliteit van navorsingsbesluite omskryf. Hierdie omskrywing kan in terme van die blok navorsingsbesluite vertaal word as 'n antwoord op die vraag: Hoe, d.w.s. deur watter besluite, moet navorsing beplan, gestruktureer en uitgevoer word om aan die eise van wetenskaplikheid te beantwoord? In die beantwoording van die vraag moet onder meer aandag geskenk word aan die determinante van navorsing, d.w.s. daardie laktore - domeinaannames, teoreties metodologiese raamwerk ensovoorts - wat bepalend is vir die beshuite wat tydens die navorsingsproses geneem word. Samevaltend: Die navorsingsmetodologie bestudeer (deskriptief) en lê riglyne neer oor (preskriptiel) die besluite wat die navorser neem in sy navorsingsaktiwiteit, sowel as die verantwoording van daardie beshuite in terme van die onderliggende domeinaannames, teoretiese en metodologiese voorkeure, navorsingsdoelstelling en -strategie sowel as die beperkinge en eise wat die navorsingsvoorwerp stel.

Die wetenskapsfilosolie konsent reer daarenteen nie soseer op die netwerk en konteks van navorsingsbesluitneming nie maar eerder op (wee andersoortige aspekte van die navorsingspraktyk: (1) Dit besin oor die aard, struktuur en dinamika van wetenskap in die algemeen, met ander woorde vergelykende studie van wetenskapsbeelde; vrae soos: Wat is die aard en struktuur van wetenskap, teorie, waarheid, objektiwiteit, ensovoorts? (2) Daarnaas moet die wetenskapsfilosofie ook aandag gec aan die interne en eksterne relasies tussen en binne die subsisteme INTELLEKTUELE KLIMAAT en MARK VAN INT'ELLEK TUELE HULPBRONNE. Die wetenskapsfilosofie skenk dus krities aandag aan die verbande tussen metateoret iese aannames en wetenskaplike teorieë, tussen teorieë en wetenskapsbeelde en veral die verband tussen wetenskapsbeelde en metodologiese modelle.

Dit sou vir die wetenskapsfilosofie as dissipline fataal wees indien slegs aan probleme van die eerste kategorie aandag gegee word. Besinnings oor objektiwiteit, waarheid en wetenskaplikheid in die algemeen verkry slegs RELEVANSIE vir die navorser indien die verband daarvan met '" bepaalde metodologiese model (en daardeur aan die besluitnemingsproses) aangetoon word (kategorie 2-probleme). Dit is dan veral op hierdie laaste grens- 


\section{Mouton}

gcbied - m.a.w. die verband tussen wetenskapsbecld en metodologiese model - waar wetenskapsfilosowe en navorsingsmetodoloë klaarblyklik moet saamwerk.

Ek sluit hierdie afdeling af met 'n kort bespreking van twee voorbeelde oor die soort samewerking wat ek in gedagte het, en bespreek die twee probleme vanuit die gesigspunt van dic wetenskapsfilosofie.

Een terrein wat myns insiens braak le, is die verskeidenheid van misverstande waarmee navorsers sit rakende die kriteria van gocic navorsing. Navorsers huldig dikwels standpunte oor objektiwiteit, feitelikheid, algemeengeldigheid, teoriect wat streng gesproke niks anders as verouderde mites is nie. In hierdie verband wys ek dus op die ontmitologiseringsfunksie van die wetenskapsfilosofic. 'n Tweede aspek van die verband tussen wetenskapsfilosofie en navorsingsmetodologie waar wetenskapsfilosowe dikwels fouteer, raak die etikettering van navorsers as positiviste, empiriste, Marxiste ensovoorts. Hierdie geneigdheid en selfs soms obsessie tot etiketlering is myns insiens 'n skreiende voorbecld van die deduktiewe denkfout (deductive fallacy).

\section{(I) Oor onlmilologusering}

Navorsers in die geesteswetenskappe huldig dikwels standpunte soos die volgende:

- Wetenskaplikheid veronderstel onbevooroordeclde waarneming en cksakte meting (Objektiwiteitsmite).

- Wetenskaplike navorsing moet gebaseer word op 'n basis van vasstaande feitc of gegewenhede wat die geldigheid van resultate waarborg (Feitelikheidsmite).

- Wetenskaplike teorieë is slegs aanvaarbaar indien dit (a) kousale verbande, of ten minste korrelasies, tussen gebeurtenisse of veranderlikes kan verklaar, en (b) algemeen geldig is (Veralgemeningsmite).

Die kenmerkende van elkeen van hierdie tesisse is dat dit afgelci is uit die positivistiese wetenskapsbeeld, 'n tradisie wat in meer as een opsig as gedatcer uitgewys en onhoudbaar is. Die metodologiese implikasies van die aanvaarding van sodanige wetenskapsbeeld was - en is - verreikend. Ek verwys na enkele tipiese aannames wat navorsers op grond van hierdie tradisie maak:

- Dat die navorser nic hipot eses/teorieë of vermocdens oor sy navorsings- 


\section{Metodologiese vraagstukke}

voorwerp vooral moet spesiliseer nie, aangesien dit 'n bevooroordeelde houding jeens die navorsingsbevindinge sou impliseer;

- dat die navorser met'n oop verstand/gemoed sy objek moet benader en die feite moet laat spreek;

- dat inligting/data wat ingewin is, gekwantifiseer moet word om wetenskaplik te wees;

- dat met statistiese ontledings van data volstaan moet word en teoretisering tot 'n minimum beperk moet word.

Soortgelyke mites sou ook geïdent ifiseer kon word wat hulle oorsprong in 'n human ist iese wetenskapsbeeld het. 'n Voorbeeld hiervan is die besware teen enige vorm van meting en kwantifisering asof dit reduserend en selfs dehumaniserend sou wees. Daar is myns insiens nog geen argument gegee wat aantoon dat daar 'n noodwendige verband tussen kwantifisering en dehumanisering - wat dit ook al in 'n navorsingskonteks sou kon beteken - bestaan nie.

\section{Oor die etiketteringsindroom}

In ons bespreking van die model is gesê dat 'n keuse vir 'n besondere wetenskapsbeeld duidelik ' $n$ invloed het op die metodologiese voorkeure sowel as op die besondere metodes en tegnieke wat die navorser gebruik. 'n Mens sou clus, myns insiens, die geregverdigde alleiding hieruit kon maak dat iemand wat 'n meer positivistiese wetenskapsbeeld voorstaan, geneig sou wees om eerder 'n kwantitatiewe as 'n kwalitatiewe metodologie te kies. Die probleem is natuurlik dat navorsers selde 'n eksplisiete of geartikuleerde wetenskapsbeeld hanteer. Hoogstens is hulle van breë onderskeidinge bewus. Meer dikwels is hulle slegs bewus van die beskikbare metodes en tegnieke in die dissipline - maar weer eens ook nie altyd van die metodologiese voorwaardes waaronder sekere metodes/tegnieke gebruik kan word nie. Die keuse van 'n navorser vir kwantitatiewe metodes en tegnicke impliseer daarom nie noodwendig ook die aanvaarding van alle aspekte van die kwantitatiewe metodologiese model, en selfs in 'n mindere mate van alle aspekte van die posit ivist iese wetenskapsbeeld nie. Wetenskapsfilosowe is geneig om navorsers wat byvoorbeeld byna uitsluitlik statistiese tegnieke van data-ontleding en kwantitatiewe tegnicke van data-insameling gebruik, deur 'n soort van guilt-by-associalion-benadering as empiriste en positiviste te etiketleer. Hierdie strategie is myns insiens nie gewoon onwetenskaplik nie - daarom dat ek dit 'n vorm van die deductive jallacy noem - maar ook kontraproduktief. As die wetenskapsfilosoof nie ook kan aanduı watter metodologiese implikasies die keuse van metodes en tegnieke 


\section{Mouton}

het nie, moet hy, soos Wittgenstein aanbevcel het, licwers swyg!

\section{METODOLOGIESE VRAAGSTUKKE - NAVORSINGSPRIORI- TEITE}

Uiteraard is daar 'n verskeidenheid van metodologiese vraagstukke wat verdere navorsing vereis. My crvaring is clat die vlak van metodologiese kennis in die Suid-Afrikaanse navorsingsgemeenskap onrusbarend laag is. Alreeds op die basiese vlak van: Hoe ontwerp ek my navorsing? steek verskeie navorsers vas, met dic gevolg dat baie navorsing ongesistemat iseerd en op ' $n$ ad hoc-basis aangepak word en ook verloop.

Ek volstaan egter met hierdie een inleidende opmerking en wys eerder op drie terreine of probleemgebiede waar daar tans interessante ont wikkelinge plaasvind en wat vir alle geesteswetenskaplikes van algemene belang is. Die drie is:

(a) die kwantitatief - kwalitatief-onderskeiding;

(b) die problematick van kruisvalidasie;

(c) die navorsingsetiek.

\section{(a) Kwantilatief-kwalitatief}

Tradisioneel was die kwantitatiewe metodologic onget wyfeld die dominante metodologiese model in die sosiale wetenskappe - en in sekere dissiplines is dit ook vandag nog die geval. Alreeds sedert die twintigerjare in die Chicagoskool onder leiding van mense soos Mead en later Blumer het die simbolicse interaksionisme en later strominge soos die etnometodologie veral in die sosiologie die weg begin baan vir ' $n$ meer kwalitaticwe benadering. ${ }^{B}$ Ook in ander vakgebiede het herlewings van vrocëre wetenskapsbeelde soos die fenomenologie en hermencutiek veral in die sestigerjare verdere steun gebied vir 'n kwalitatiewe benadcring van navorsing. Geleidclik het daar ook 'n literatuur ontstaan in veral dic sosiologie van afwykende gedrag wat dic metodologiesc gesofistikcerdheid van die kwalitatiewe model onderstreep het.

Die vraag wat tans gedebatteer word, is in watter mate die kwantitatiewe benadering en kwalitatiewe benadering versoenbaar is. Sommige skrywers (Rist, 1977) beskou dit in 'n Kuhniaanse sin as twee wedersyds uitsluitende paradigmas. "Ultimately, the issue is not research strategies, per se. Rather, the adherence to one paradigm as opposed to an other predisposes one to view the world and the events within it in profoundly dillering ways. "In terme 


\section{Metodologiese vraagstukke}

van my model impliseer dit uitsluiting van byvoorbeeld die positivistiese en humanistiese wetenskapsbeelde cerder as kwantitatiewe en kwalitatiewe modelle. In 'n intensiewe ondersoek na die basiese verskilpunte tussen hierdie twee benaderings, in 'n artikel met die veelseggende titel "Beyond Qualitative versus Quantitative methods" bevind Reichardt en Cook die teendeel. ${ }^{10}$ Die interessante van hulle artikel egter is dat hulle nie Kuhn se incommensurability tesis aanvaar nie en, daarmee saam, 'n voorkeur het om van kwantitatiewe en kwalitatiewe melodes cerder as paradigmas of modelle of metodologieë te praat. Dit illustreer egter ook 'n vroeëre bewering van my, nl. dat navorsers dikwels meer geïnteresseerd is in die toepaslikheid van metodes en tegnieke as die ingewikkelde (en dikwels meersinnige)metodologiese en wetenskapsfilosoliese debatte oor die onderliggende metodologiese modelle en wetenskapsbeelde. Die uitdaging word gerig aan die metodoloog en wetenskapsfilosoof om op logiese en heldere wyse aan te toon watter praktiese besluitnemingsimplikasies hierdie breëre konteks uitoefen.

\section{(b) Kruisvalidasie}

Verskeie bekende metodoloë soos Donald Campbell, ${ }^{11}$ Eugene Webb ${ }^{12}$ en Norman Denzin het al sedert die 1950-erjare geargumenteer vir die gebruik van meervoudige metodes, teorieë en databronne in een enkele navorsingsprojek. Dit is veral Denzin wat in die tweede uitgawe van sy The Research Act (1978) uitvoerig ingaan op die hele problematiek van "triangulation", wat ek as kruisvalidasie vertaal. Ek haal hom aan as waarskynlik dan die mees geartikuleerde standpunt in hierdie verband:

"Sociology's empirical reality is a reality of competing definitions, attitudes and personal values. As such, it is a social object in the symbolic environment of the scientists ...... The act of doing research is an act of symbolic interaction. Each sociological method and, in fact, each sociologist generate different lines of action toward this object. Thus, complete agreement between methods and their users can never be expected ...... Triangulation, or the use of multiple methods, is a plan of action that will raise sociologist above the personalist ic biases then stem from single methodologies. By combining methods and investigators in the same study, observers can partially overcome the deficiencies that flow from one investigator or one method."

Denzin gaan dan voort om vier soorte/vorme van kruisvalidasie te bespreek: kruisvalidasie deur gebruikmaking van meerdere databronne, meerdere navorsers, meer as een teoretiese perspektief en meerdere metodes en tegnieke. 


\section{Mouton}

Die primêre oogmerk met kruisvalidasic is natuurlik om 'n optimale graad van konvergensic van navorsingsresultate te kry. 'n Intcressante nuwc perspekticf op hierdie problematiek vind ons in die onlangse artikel van Janet Lever oor "Mult iple methods of data collection" 15 , waarin sy aantoon dat die gebruik van meervoudige metodes natuurlik ook tot divergente bevindinge lei. Sy toon egter deur haar studie aan dat ook dit positiewe implikasics vir metodologie besit, aangesien sekere onderliggende of verborge faktore wat andersins ongemerk sou gaan, dan na die oppervlak kom en betekenisvolle interpretasie moontlik maak.

\section{(c) Navorsingsetiek}

Die problematick van navorsingsetiek is natuurlik nie 'n resente probleem nie. Nie alleen in eksperimentele ontwerpe is vroeg al besef dat et iese riglyne noodsaaklik is om beide eksperimenteerder na navorsingsubjek te beskerm nie, maar ook in declnemende waarnemingstudies (bedek en openlik) het aspckte soos die inbreuk maak op mense se privaatheid en die misleiding van navorsingsubjekte ooglopende morele herbesinning meegebring. Alhoewel navorsing ook op hierdie gebiede daarom uiters noodsaaklik is, is dit dic afgelope aantal jarc met die opkoms en toename van kwalitatiewe studies dat die multidimensionaliteit van navorsingsetiek gewcldig sterk op die voorgrond getrce het.

Ek wys op enkcle interessante aspekte. Tipiesc kwalitatiewe metodes en tegnieke soos koverte dcelncmende waarneming, indicpteonderhoudvoering, koverte en overte nat uralistiese waarneming, raadpleeg van outobiografieë, dagboeke, memoirs, ens. impliseer onvermydelik 'n veel nouer betrokkenheid van navorser met navorsingsubjek. Naas tradisionele navorsingsetiese probleme beteken dit ook die ontstaan van nuwe probleme - die problematiek van individuele vryheid en privaathcid word veel groter, die problematiek van misleiding word ernstiger ${ }^{16}$ en - interessant genoeg -ook die navorser kom in nuwe morele dilemmas te staan. Onder meer omdat hy mense mislei, koverte rolle moet speel en dikwels in konfliksituasies te staan kom of - posit iewer - as gevolg van die noue betrokkenheid by sy respondente verkry hy al hoe meer vertroulike en persoonlike inligting, word hy as 'n vertroueling beskou, word dikwels 'n persoonlike vriend van die respondent, met die gevolg dat hy ook emosionecl oorbelas word.

Alhoewel 'n onlangse werk onder redaksie van Martin Bulmer ${ }^{17}$ baie van hierdie probleme onder die loep neem, is dit ooglopend 'n voorkeur op die gebied van die wetenskapsfilosolie cn navorsingsmetodologie. 


\section{Metodologiese vraagstukke}

Ek sluit op 'n ligter noot af:

Teen die agtergrond van my opmerkings oor koverte deelnemende waarneming skryf Laud Humphreys in 1970 die volgende:

"Any man who remains in a public restroom for more than live minutes is apt to be either a member of the vice squad or someone on the make. As yet, he is not suspected of being a social scientist".

\section{VERWYSINGS}

1. Hindess, B., 1977, Philosophy and methodology in the social sciences, Sussex, The Harvester Press.

2. A.w., p. 4.

3. Idem, p. 6

4. Sperber, I., 1978, Methodology as a changing field of specialization, (IN Swanson, CH. (ed), Focus: Unexplared de Viance, Guillord, Dushkin Publ. Group p. $198-205)$.

5. Vergelyk Iny artikel oor hierdie begrippe in die Navorsingsbulletin Tydshrif van die SAPGN: On the meaning of "philosophy of science", "research methodology" and "research technology", 13(3): 33-37, 1983. Ter verduideliking is dit ook nodig dat ek hier sal verwys na 'n ander artikel van my waarin dieselfde sisteemteoretiese model van die navorsingspraktyk gebruik word en wat dus gedeeltelik met hierdie artikel oorvleuel: Kwantitatietee en kualitatienue metodologieë in die geesteswetenskappe in die Suid-Afrikaanse Tydsknf vir Sosiologie vol. 14(4) $124-131,1983$.

6. Radnitzky, G., 1970. Contemporary schools of metascience, 2de uitgawe, Göteborg, Akademiforlaget.

7. Kuhn, T.S., 1962, The structure of scientific revolutions, Chicago, The University of Chicago Press.

8. Vergelyk die artikels van Wilcy en Bealer in Contemporary issues in theory and research: $A$ metasociological perspective, onder redaksie van William Snizek et al., 1979, London, Aldwych Press. 


\section{Mouton}

9. Rist, R.C., 1977, On the relations among educational research paradigms, IN Anthroplogy and Education Quarterly, 8:42-49.

10. Reichardt, C., \& Cook, T., 1979, Beyond qualitalive versus quantitative methods (IN Cook, T. \& Rcichardt, C. (reds). Qualitative and quantitative methods in evaluation research, Sage Publications, p. 7-32).

11. Campbell, D.T. \& Fiske, D.W. 1959, Convergent and discriminant validation by the multitrait - multimethod matrix IN Psychological Bulletin 56 $(27: 81-10)$.

12. Webb, E.J. et al., 1966, Unobtrusive measures: Nonreactive research in the social sciences, Chicago, Rand McNalty.

13. Denzin, N., 1978, The research act, 2de uitgawe. New York, McGraw-Hill.

14. A.w., p. 291.

15. Lever, J., 1981, Multiple methods of dala collection, Urban Life 10:199-213.

16. Vergelyk die artikels van Laud Humphreys en Simon Holdoway in die versamelbundel van Martin Bulmer (volgende verwysing).

17. Bulmer, M., 1982 Social reasearch ethics, London, The MacMillan Press. 